\title{
FACTORS AFFECTING CONSUMER ACCEPTANCE TOWARDS OMNICHANNEL APPROACH WITH REFERENCE TO SUPERMARKET SECTOR
}

\author{
Peiris, H. Y. D. \\ Department of Marketing Management, \\ University of Sri Jayewardenepura \\ yomal96@gmail.com \\ Lakshika, V.G.P. \\ pavani@sjp.ac.lk \\ Rasanjalee, R.M.K.S. \\ Faculty of Management Studies, \\ Sri Lanka Technological Campus \\ samudrikar@sltc.ac.lk
}

\begin{abstract}
The revolutionary development of technology has evolved the retail world drastically in recent decades in terms of using digital and physical platforms to provide unique experiences to consumers. Consumers prefer moving seamlessly between physical and online channels according to their time, convenience, choice, etc. Omnichannel approach is a novel approach that aims to provide seamless experience to consumers by using both online and physical channels. All the channels are integrated to provide the same experience through any touchpoint. By using Omnichannel approach companies target the same consumers via different channels to provide a unique experience. The purpose of this study is to understand factors affecting consumer acceptance towards an Omnichannel approach and the study has been conducted with reference to supermarket sector. A quantitative study was conducted with 256 employed individuals in the Colombo district of Sri Lanka, and a self-administered questionnaire was used,
\end{abstract}


with data analyzed using Structural Equation Modelling (SEM) with AMOS. The results of the study indicated that perceived usefulness and compatibility have a significant positive impact, while the perceived ease of use, cost and risk do not have a significant impact on consumers' behavioral intention to use an Omnichannel approach. Perceived compatibility is the salient factor out of selected variables. This study contributes to academic research by shedding light on this novel phenomenon, as well as to businesses operating in the supermarket sector by drawing numerous implications for developing their omni-channel strategy.

Keywords: Consumer Acceptance; Omnichannel Approach; Supermarkets 


\section{Introduction}

The retail world has changed dramatically in recent decades and has become more sophisticated with the revolutionary development of technology, digital marketing, and e-commerce(Verhoef, Kannan, \& Inman, 2015). Further, alternative distribution channels, which have proliferated alongside technological advancements, have also altered retailing perspectives. Besides, when choosing channels for purchases consumers move between physical stores, online or mobile stores according to the preferences, situation, considering time period and the product category (Silva et al., 2018). As a result, retailers today recognize that each channel, such as online, physical and mobile has distinct advantages, and they strive to reach their customers through a variety of channels (Levy and Weitz, 2001).

Moreover, in the current context, consumers have become more knowledgeable and advanced. They seek unique experiences when purchasing products rather than just purchasing products from stores (Carvalho, 2014). According to Chief Marketing Officer Council report, (2019) over $85 \%$ of global consumers prefer a blend of both digital and physical channel experiences when interacting with brands especially in supermarket sector. Only $10 \%$ prefer only digital channels and only $5 \%$ of consumers prefer only physical channels. Even though most of the consumers prefer both digital and physical channels only $13 \%$ of consumers believe companies are meeting their expectations via both of these channels. Therefore, many retailers have developed multichannel strategies to deal with these technological advancements by adding new touch-points to their portfolios through which they can interact with customers (Verhoef et al., 2007).

In multichannel, each channel targets a separate segment of consumers and even serves different needs, but consumers could not move seamlessly in online and physical channels. As a result, a novel concept known as the Omnichannel approach has emerged to provide consumers with a seamless experience by integrating both online and offline channels (Rigby, 2011; Carvalho, 2014; Sopadjieva et al., 2017; Silva et al., 2018). Although academic literature on omnichannel retailing has been appearing since 2015, studies relating to this new paradigm are still scant (Verhoef, Kannan, \& Inman, 2015). However, while 
these approaches are not widely used in Asian countries at the moment, they are transitioning to using online and physical approaches to provide consumers with unique experiences, and thus there is a high potential in using Omnichannel approaches (Konrad Chan, 2020), which motivated the current study to investigate consumer acceptance of this new paradigm in an Asian context.

Further to that, the emergence of omni-channel retailing expands opportunities for academics to generate insights that can help retailers address challenges. Because companies can gain a competitive advantage by using an omnichannel approach, hence both practitioners and researchers are keenly interested in consumer intentions to use this type of approach (Silva et al., 2018).

However, previous literature indicated that studies relating to Omnichannel approach have been relatively scanty and out of the few studies, far too little attention has been paid to investigate consumer acceptance towards Omnichannel approach (Verhoef et al., 2015). Furthermore, studies on Omnichannel approach in Asian countries are rare and as a developing country, in Sri Lanka, no attempts were done to explore the potential of Omnichannel approach (Muhamed, 2019). Therefore, this study strives to understand the key factors underlying consumers' intentions to use an omnichannel approach.

Besides that, consumer penetration of supermarket shopping in Sri Lanka has more than doubled in the last decade, with an average year-over-year growth rate of 7.3 percent (Dissanayake, 2019), demonstrating that the industry's growth has been consistent and sustainable. It should be noted, however, that all the previous studies on supermarket industry that are reported in open literature have not been given attention to investigate Omnichannel approach, Hence, the present study aims to investigate factors affecting consumer acceptance towards Omnichannel Approach in Sri Lankan context with special reference to supermarket sector.

Accordingly, the present study will contribute to the literature by bridging the knowledge gaps in Sri Lankan context identifying factors that influence consumers to use Omnichannel approaches. More specifically, this paper examines the impact of compatibility, cost, perceived risk, perceived usefulness, and perceived ease of use on behavioral intention to use. Because the majority of the open literature on 
technology acceptance-based research areas has used the TAM model to identify factors and other factors such as compatibility, risk, and cost mostly explain the adoption of innovations (Davis, 1986; Ventatesh et al., 2012)

\section{Literature Review}

In the current context, consumers can interact with a brand through many touchpoints. They can use mobile devices while they are physically in the store, to quickly check the price and availability of the products and to compare products with different retailers. This channel strategy is viewed as Omnichannel approach. There, customers can seamlessly move across both online and physical channels while getting the same experience. Here all the channels are integrated to provide customers a unique experience (Sopadjieva et al., 2017).

The word Omnichannel is derived from the term "Omni" itself which is a Latin word meaning "all" or "universal", (Sopadjieva et al., 2017) and according to Cambridge Dictionaries (2014), the prefix "Omni" means "everywhere" or "everything" which emphasis on integrating everything of different channel approaches. Rigby, (2011) was the first to use the expression Omnichannel approach as, "an integrated sales experience that melds the advantages of physical stores with the information-rich experience of online shopping". According to Piotrowicz \& Cuthbertson,(2014)Omnichannel concept is perceived as an evolution of the multichannel. In Sopadjieva et al., (2017), the author identifies Omnichannel in consumer experience point of view which provides consumer experience across the channels and touchpoints. According to above definitions, the main idea of Omnichannel approach is providing seamless experience to consumers by using both physical and online channels, and all the channels used are integrated to provide a unique experience to a particular target group of consumers.

Getting an understanding about consumer acceptance on innovative technologies is important in this study. Due to vast development of technologies, consumer behavior also rapidly changing. Consumers expect consistent and integrated product or service experience regardless of the channel they use to purchase products. Consumers' acceptance behavior will depend on preferences, situation, time, product category, recommendations, and past experiences (Davis et al., 1989). 
Presently, consumer behavior has become important for internet-based businesses (Wu \& Wang, 2005). Consumers use computers or mobile devices in purchasing and using products and consumer expectations have changed over time. Since Omnichannel approach is a technological approach, it needs to be investigated whether consumers accept this kind of approach and what are factors that influence the decision of the consumers.

According to the literature, the important model to investigate factors of technology acceptance is, Technology Acceptance Model (TAM) (Davis et al., 1989) According to TAM perceived usefulness and perceived ease of use can be considered as two factors that decide consumer acceptance of this technologybased approach (Davis et al., 1989).

\section{Perceived Usefulness}

This can be defined as the degree to which a consumer believes and perceives that using a particular technology would enhance his or her experience when engaging with a product or service (Davis et al., 1989). According to the literature, most of the scholars have investigated that perceived usefulness has a positive effect on behavioral intention to use an Omnichannel approach by the consumers (Davis et al., 1989; Wu \& Wang 2005; Silva et al.,2018). Therefore, to conduct this study following hypothesis has been formulated:

H1: Perceived usefulness has a positive impact on behavioral intention to use an Omnichannel approach.

Perceived Ease of Use

Perceived ease of use refers to the degree to which a consumer believes and perceives that using a specific technology would be free of effort (Davis et al., 1989). This can be explained by the word ease which means freedom from difficulty or hard effort. According to literature most of the scholars have investigated that perceived usefulness has a positive effect on behavioral intention to use an Omnichannel approach and most importantly research studies conducted in the Asian region have found the same (Davis et al., 1989; Wu \& Wang 2005; Kim et al., 2010; Silva et al.,2018). Therefore, to conduct this study following hypothesis has been formulated: 
H2: Perceived ease of use has a positive impact on behavioral intention to use an Omnichannel approach.

According to previous studies, perceived compatibility is a factor that decides consumer acceptance because if the particular technology is not compatible with the user, they cannot view it as useful.

\section{Perceived Compatibility}

Compatibility can be defined as the degree to which technological innovation is perceived as consistent with the existing values, past experiences, habits, lifestyle, and needs of potential adopters Rogers (1983). Moreover, when using online channels, they should be compatible with that target consumers (Silva et al., 2018). According to literature most of the scholars have found that perceived compatibility has a positive effect on intention to use an Omnichannel approach and further it was confirmed by the most recent study on Omnichannel approach (Chen et al.,2002; Wu \& Wang 2005; Kim et al., 2010; Silva et al.,2018). Therefore, to conduct this study following hypothesis has been formulated:

H3: Perceived compatibility has a positive impact on behavioral intention to use an Omnichannel approach.

Another factor to determine consumer acceptance of Omnichannel approach is Cost. Consumers make behavioral choices by comparing costs with benefits they get from using products and services (Venkatesh et al., 2012).

Cost

Consumers have to bear costs like equipment costs, access costs, transactional fees when using Omnichannel approach. Consumers make their decisions by comparing cost with the benefits that they could get from consuming products and cost is an important factor of consumers' intention to accept technologies (Wu \& Wang, 2005). According to literature, most scholars have found that Cost has a negative effect on intention to use an Omnichannel approach and further it was confirmed by the most recent study on Omnichannel approach (Wu \& Wang 2005; Silva et al.,2018). Therefore, to conduct this study following hypothesis has been formulated: 
H4: Cost has a negative impact on behavioral intention to use an Omnichannel approach.

Accepting online approaches involves a certain degree of uncertainty that customers may perceive some form of risk and it may affect consumer decisions. Therefore, Risk is selected as a factor that determines consumer acceptance (Silva et al., 2018).

\section{Perceived Risk}

All online activities involve some degree of uncertainty and during online transactions, consumers may feel some risk. Perceived risk can be identified in three types; Performance risk, in which consumers may feel uncertainty of products may not function up to the expected level, Financial risk, which is the possibility of financial losses and Privacy risk, which is the uncertainty related to providing personal information to a seller (Silva et al., 2018). According to the literature, most recent studies on Omnichannel approach have investigated that there is a negative effect of perceived risk on intention to use an Omnichannel approach (Silva et al., 2018). Therefore, to conduct this study following hypothesis has been formulated:

H5: Perceived risk has a negative impact on behavioral intention to use an Omnichannel approach.

\section{Conceptual Framework}

According to Figure 4, the conceptual framework of the study was developed based on hypothesis developed for the study and by a rigorous literature review.

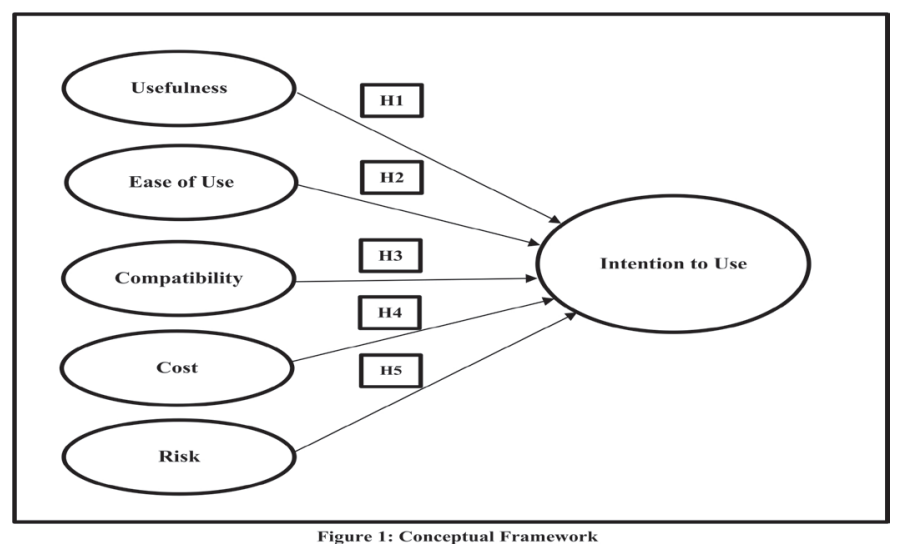




\section{Methodology}

The research philosophy of this study is Positivism because this study is based on research questions which going to be tested and confirmed by relevant hypotheses and conducted as quantitative research which starts with a theory and after a comprehensive review of academic literature then tests the theory by using hypotheses. The study used deductive research approach and used survey method whichallowed to collectquantitativedataandanalyzeusing statisticalmethods. Mono method was used as the methodological choice and the time horizon for the study will be single cross-sectional as data were collected at one time (Saunders et al., 2019). Survey questionnaires were used to collect primary data and used both primary and secondary data sources. According to Sri Lanka Labor Force Survey Annual Report (2019) over 18 years individuals are considered as working-age population. Therefore, the population of the study identified as employed individuals aged over 18 years in Colombo district. Sampling element was identified as employed individuals aged over 18 years living in Colombo district in Sri Lanka. Judgment Sampling technique was used to collect specialized informed inputs for the study where the researcher collects data from only employed individuals who have purchasing power in Colombo District (Sekaran, 2016). Unit of analysis is individual consumers and the sample size for the study is 256 respondents. According to Silva et al., (2018) Likert Scale was selected to gather information from the respondents for the study. Five-point scale includes following anchors; 1 = Strongly Disagree, $2=$ Disagree, $3=$ Neither Agree nor Disagree, $4=$ Agree, 5 = Strongly Agree (Sekaran, 2016). According to Sekaran, (2016) to conduct this study, a structured questionnaire was developed according to the literature. The data collection was conducted as an online survey and the language used was English.

\section{Data Analysis and Findings}

Data preparation processes were conducted to ensure collected data are accurate, complete, and suitable for further analysis (Sekaran, 2016). Outliers and missing values were initially addressed with IBM SPSS 21.0 software. The data cleaning process was followed by the demographic analysis (table 02) and the multivariate assumptions (Hair et al, 2019). The Analysis of Moment Structures (AMOS) 
20.0 statistical analysis software was used in conducting the Structural Equation Modelling (SEM) which incorporated two major steps as developing the measurement model followed by the structural model. Subsequently, the Goodness of Fit indices was assessed in measuring the model adequacy.

Table 2: Profile of the Respondents

\begin{tabular}{|c|c|c|c|}
\hline Gender & & Work Situation & \\
\hline Male & $58.20 \%$ & Full time worker & $42.5 \%$ \\
\hline Female & $41.80 \%$ & Working Student & $37.3 \%$ \\
\hline Age & & Part time worker & $6.8 \%$ \\
\hline Younger millennials & $58.59 \%$ & Self employed & $5.9 \%$ \\
\hline Older millennials & $24.61 \%$ & Other & $3.4 \%$ \\
\hline Generation X & $8.47 \%$ & Entrepreneur & $1.7 \%$ \\
\hline Baby Boomers & $4.24 \%$ & Businessman & $0.8 \%$ \\
\hline Education Level & & Full-time student & $0.8 \%$ \\
\hline Undergraduate & $61.9 \%$ & Unemployed & $0.8 \%$ \\
\hline Graduate & $22.9 \%$ & Monthly Income & \\
\hline Postgraduate & $5.9 \%$ & Rs.25 000 and below & $51.69 \%$ \\
\hline Doctoral & $0.8 \%$ & Rs.25 000 - Rs.50 000 & $18.64 \%$ \\
\hline MBA & $0.8 \%$ & Rs.50 000 - Rs.75 000 & $7.63 \%$ \\
\hline Advanced Level & $5.9 \%$ & RS.75 000 - Rs. 100000 & $9.32 \%$ \\
\hline Ordinary Level & $1.8 \%$ & Rs. 100000 or above & $12.71 \%$ \\
\hline \multicolumn{2}{|c|}{ Awareness of Omnichannel approach } & \multicolumn{2}{|c|}{$\begin{array}{l}\text { Frequency of using Omnichannel } \\
\text { approach }\end{array}$} \\
\hline Aware & $66.1 \%$ & Always & $5.93 \%$ \\
\hline Not Aware & $33.9 \%$ & Never & $22.03 \%$ \\
\hline \multicolumn{2}{|l|}{ Preferences of Respondents } & Often & $17.80 \%$ \\
\hline Visiting stores & $30 \%$ & Rarely & $15.25 \%$ \\
\hline $\begin{array}{l}\text { Blend of digital and } \\
\text { physical platforms }\end{array}$ & $70 \%$ & Sometimes & $38.98 \%$ \\
\hline
\end{tabular}

Source: Survey Data 
According to the Department of Census and Statistics percentage of labor force participation in Colombo district amounts to more than $50 \%$ of males. Therefore, the gender composition of the sample aligns with the population. Emily A. Vogels, (2019) stated, technological usage of millennials is greater than other generations and since the study considered only employed individuals, the sample represented a larger portion of employed respondents. According to findings most of the respondents use Omnichannel approach for their purchases. Pearson Chi-Square test conducted for Frequency and Income, indicated there was a significant relationship between the frequency of using Omnichannel approach and the income of the respondents.

\section{Measurement model}

Harman's Single Factor technique (Podsakoff et al., 2003) and the One-way ANOVA test were used to conduct bias testing, which demonstrated that common method bias and non-response bias were not present. The Analysis of Moment Structures (AMOS) 20.0 statistical analysis program was used to do Structural Equation Modelling (SEM) with the confirmation of multivariate assumptions. By confirming the threshold values, the study established discriminant validity (Fornell \& Larcker, 1981) and reliability, whilst factor loadings greater than 0.7 confirmed convergent validity (Hair et al., 2019) as illustrated by table 03 .

Table 3: Validity and Reliability Measures

\begin{tabular}{|c|c|c|c|c|c|c|c|c|c|c|c|}
\hline \multirow{2}{*}{ 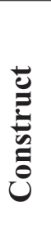 } & \multirow{2}{*}{ 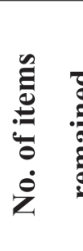 } & \multirow{2}{*}{ 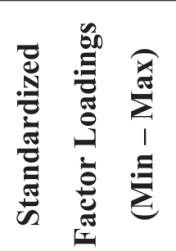 } & \multirow[t]{2}{*}{ AVE } & \multirow[t]{2}{*}{ CR } & \multirow{2}{*}{$\begin{array}{l}\text { Cron } \\
\text { bach' } \\
\text { s } \\
\text { Alpha }\end{array}$} & \multicolumn{6}{|c|}{ AVE vs SMC } \\
\hline & & & & & & $\mathbf{P U}$ & PE & PC & $\mathrm{C}$ & $\mathbf{R}$ & IU \\
\hline $\mathrm{PU}$ & 04 & $0.697-0.781$ & 0.658 & 0.875 & 0.806 & 0.658 & & & & & \\
\hline $\mathrm{PE}$ & 03 & $0.807-0.856$ & 0.687 & 0.868 & 0.773 & .0004 & 0.687 & & & & \\
\hline PC & 03 & $0.823-0.835$ & 0.772 & 0.911 & 0.851 & .0060 & .0000 & 0.772 & & & \\
\hline $\mathrm{C}$ & 03 & $0.867-0.880$ & 0.765 & 0.907 & 0.841 & .0384 & .0018 & .2314 & 0.765 & & \\
\hline $\mathrm{R}$ & 04 & $0.754-0.847$ & 0.685 & 0.897 & 0.846 & .0024 & .0000 & .5178 & .3248 & 0.685 & \\
\hline IU & 04 & $0.820-0.863$ & 0.726 & 0.914 & 0.872 & .3832 & .0002 & .3969 & .3795 & .3612 & 0.726 \\
\hline
\end{tabular}

Notes: $\mathrm{PU}=$ Perceived Usefulness, $\mathrm{PE}=$ Ease of Use, $\mathrm{PC}=$ Compatibility. $\mathrm{C}=$ Cost, $\mathrm{R}=$ Risk, $\mathrm{IU}=$ Intention to use 


\section{Structural Model}

Structural model was established to verify the path significance at a 5 percent confidence level. Table 4 represents the data fit indices of the structural model developed. CMIN/DF value of 2.163 being below the threshold value of 3.0 reflects the absolute fit. Incremental indices being closer to 0.9 confirms that the construct is fit with the baseline model that is under the assumption that all the observed variables are uncorrelated (Hair et al., 2017). Table 5 reflects the assessment of the hypotheses established on the direct paths of the paper.

\section{Table 4: GOF Indices of the Structural Model}

\begin{tabular}{|c|c|c|c|c|c|c|c|c|c|c|}
\hline \multicolumn{5}{|c|}{ Absolute fit } & \multicolumn{3}{|c|}{ Incremental fit } & \multicolumn{3}{|c|}{$\begin{array}{c}\text { Parsimony adjusted } \\
\text { measures }\end{array}$} \\
\hline CMIN/DF & GFI & AGFI & RMR & RMSEA & IFI & TLI & CFI & PRATIO & PNFI & PCFI \\
\hline 2.163 & .915 & .886 & .042 & .055 & .968 & .961 & .968 & .819 & .772 & .793 \\
\hline
\end{tabular}

Source: Survey Data 


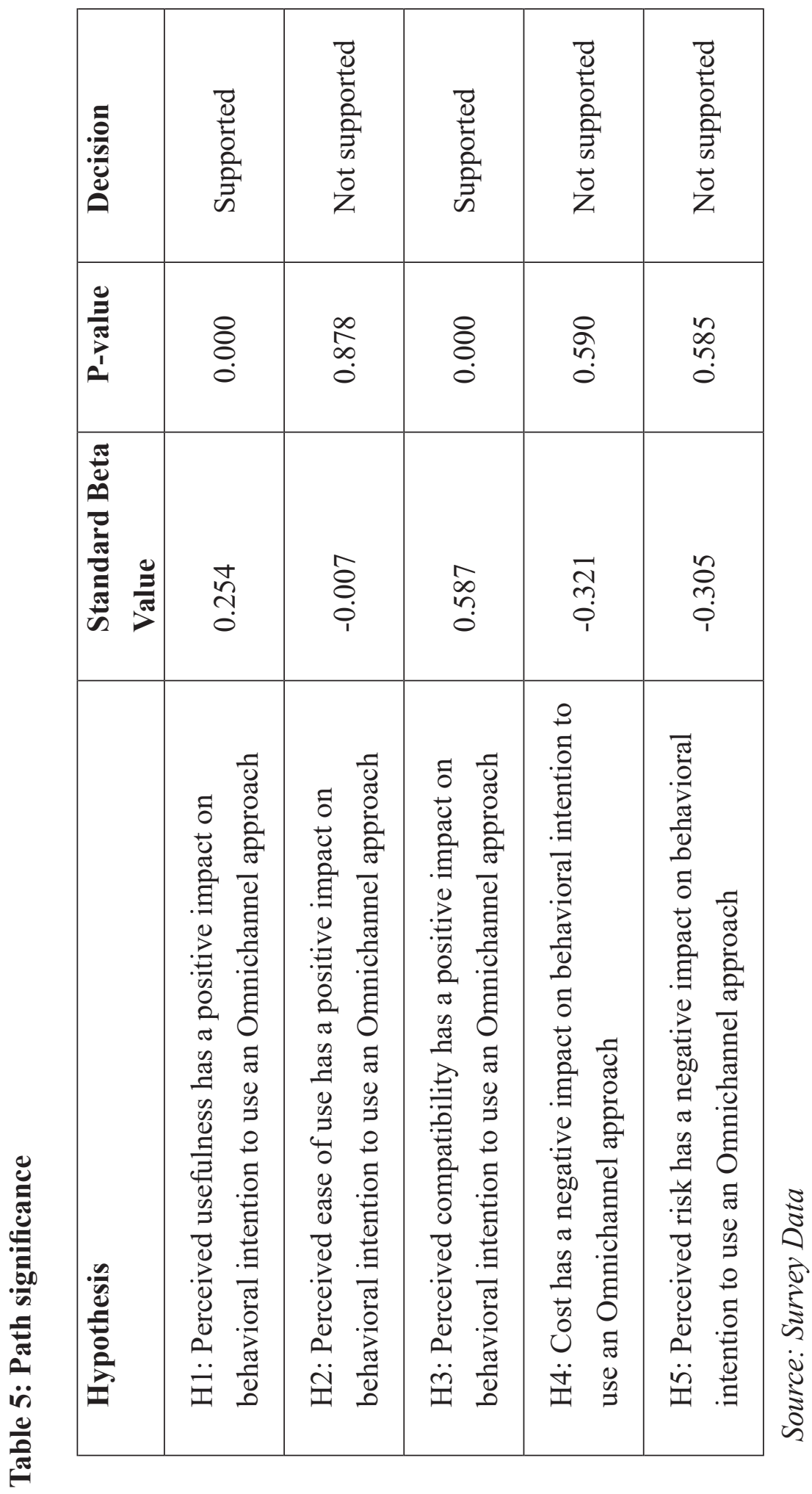


As illustrated in Table 5; perceived usefulness and perceived compatibility are supported with path significance as significant factors that affect consumer behavioral intention to use an Omnichannel approach (Sig. value $<0.05$ ). However, perceived ease of use, cost and risk are reported as insignificant factors of consumer behavioral intention to use an Omnichannel approach (Sig. value $>0.05$ ) with the path significance being not supported by the results. Further, with perceived compatibility reflected with the highest coefficient value it is considered as the salient factor affecting consumer behavioral intention to use an Omnichannel approach.

\section{Discussions, Implications and Conclusion}

As investigated, consumers' perceived usefulness has a positive impact on their behavioral intention to use an Omnichannel approach and further confirmed by similar studies (Davis et al., 1989; Wu \& Wang, 2005; Silva et al., 2018). In Sri Lanka, most supermarket companies are moving to Omnichannel approach to serving their consumers in unique ways (Muhamed, 2019). Even though they are moving to Omnichannel approach usefulness of the concept to consumers should be investigated before moving to Omnichannel approach because, as confirmed by the study perceive usefulness of consumers has a significant impact on intention to use of Omnichannel approach. Otherwise, investments of companies on Omnichannel approach will be wasted if the consumers do not perceive it as useful to their purchase intention.

The study suggests that perceived compatibility has a positive impact on consumers' behavioral intention to use an Omnichannel approach and this result agrees with similar studies (Plouffe et al., 2001; Wu \& Wang, 2005; Silva et al., 2018). Consumers consider innovations or technological platforms need to be consistent with their lifestyle, existing values, past experiences and habits in order to perceive a platform as compatible (Silva et al., 2018). Sri Lanka is considered a collectivist country with cultural beliefs and people have rich traditional and cultural considerations. (Samarasinghe, 2017). When introducing a novel approach like Omnichannel approach concerning the compatibility perceived by consumers is important especially in Sri Lanka in terms of lifestyle, social beliefs, norms, traditions, etc. 
However, the finding of the present study suggest that perceived ease of use does not have a significant impact on consumers' behavioral intention to use an Omnichannel approach, and it is further confirmed by similar study findings (Koufaris. 2002; Wu \& Wang, 2005). According to literature when consumers get experience in using a technological system over a time period it becomes the get used for it and it becomes easy to use (Koufaris. 2002). Therefore, ease of use will not significantly affect consumers' behavioral intention to use an Omnichannel approach. In Sri Lanka, computer literacy is $30.8 \%$ and significantly increasing (Department of Census and Statistic, 2019). Further, there are 149\% of mobile phone users from the total population. Since Sri Lanka has a significant rate of computer literacy and mobile penetration this finding can relate to Sri Lankan consumers and market conditions.

Study findings argue that cost does not have a significant impact on consumers' behavioral intention to use an Omnichannel approach. This is reflected by Wu \& Wang, (2005) and Silva et al., (2018) which stated, consumers who use Omnichannel approaches are already internet and digital device users and they have already beard the cost of using digital platforms. Hence, using Omnichannel approach will not increase the cost or arise additional costs (Wu \& Wang, 2005; Silva et al., 2018). Therefore, consumers do not think cost is a significant factor when using Omnichannel approaches. According to "www.hootsuite.com" statistics, there are $47 \%$ of internet penetration and $149 \%$ of mobile phone connections among Sri Lankan consumers who have already bearded the cost of using Omnichannel approach thereby it would not have an impact on consumers' behavioral intention to use an Omnichannel approach in Sri Lankan context.

The present study also suggests risk perceived by consumers does not have a significant impact on consumers' behavioral intention to use an Omnichannel approach and it agrees with the results of a similar study (Silva et al., 2018). Consumers already have an online presence when using Omnichannel approach and they already deal with risks associated with online platforms. Thereby it would not increase risk or arise additional risks with their purchases through Omnichannel approaches. According to "www.hootsuite.com" statistics, 12.7\% of Sri Lankan population are doing online transactions and $7.7 \%$ of the population 
has a mobile money account or credit card used for online purchasing. Therefore, risk perceived by consumers for online presence has been set off with the increase of online purchases in Sri Lanka and thereby it would not have an impact on consumers' behavioral intention to use an Omnichannel approach.

As investigated the salient factor affecting consumers' behavioral intention to use an Omnichannel approach is perceived compatibility and it agrees relatively well with similar studies (Wu \& Wang, 2005; Silva et al., 2018) When consumers adopting to use technologies it should be compatible or align with their lifestyle, values, beliefs and behaviors (Plouffe et al., 2001; Wu \& Wang, 2005). When introducing Omnichannel approach in Sri Lankan supermarkets companies need to be more concerned with making it more compatible with consumers in terms of local cultural beliefs, values and lifestyle of the consumers (Dissanayake, 2019).

Present study findings evidence that there is a high level of awareness about Omnichannel approach among respondents. However, this contrary to Silva et al., (2018), a study conducted in Portugal which stated that Omnichannel approach is a novel concept to consumers. There is no significant relationship between awareness of respondents and education level of the respondents which suggests companies can move to Omnichannel approach regardless of the education level of the target consumer. There is a significant relationship between frequency of using Omnichannel approach and monthly income of the respondents. More frequent users of Omnichannel approach have a relatively high income than less frequent users. This finding can also be important for supermarket sector when choosing target markets for channel strategies. Most of the respondents prefer both physical and online channels for their purchases which is a favorable condition for Omnichannel approach and further confirmed by similar studies (Silva et al., 2018). Few respondents prefer to use only physical channels or only online channels. Therefore, using Omnichannel approach in supermarket sector will be more successful in Sri Lanka since consumers prefer a blend of online and physical channels. 


\subsection{Theoretical and Managerial Implications}

This study contributes to the extant literature in several ways. Studies on Omnichannel approach cannot be seen frequently in current literature and out of few studies, it has been given little attention to investigate consumer acceptance towards Omnichannel approach (Rigby, 2011; Verhoef et al., 2015). Further, studies on Omnichannel approach in the Asian context are rare and as a developing country, in Sri Lanka no research has been found that surveyed Omnichannel approach (Muhamed, 2019). By conducting the present study this knowledge gap has been fulfilled. In addition, this study set out to determine consumer behavior towards Omnichannel approach and according to literature reviews factors influencing consumers behavior towards Omnichannel approach should be investigated with relevant to market conditions of the focal country (Lazaris et al., 2014). Unfortunately, in Sri Lankan context few studies have been carried out on investigating consumer acceptance towards Omnichannel approach (Dissanayake, 2019) and this study has contributed to the literature by bridging that gap. As a technology acceptance related research area, the study has considered updated versions of models and a combination of models to determine the factors for the study other than using common factors (Wu \& Wang, 2005). Therefore, the study has used TAM model and used perceived usefulness and ease of use and it has been extended by using factors like compatibility, cost and risk which will contribute to the literature as new knowledge generated from this study (Davis, 1986). Furthermore, previous studies related to supermarket industry have not been conducted to investigate Omnichannel approach. Since in Sri Lankan context supermarket sector is rapidly developing, this study was undertaken to evaluate factors affecting consumer acceptance towards Omnichannel approach in supermarket sector.

Findings of the study provide valuable insights and managerial implications. Omnichannel approach is a novel concept to Sri Lanka and this research will serve as a base for future investors and companies to take their strategic decisions when investing in Omnichannel approach. Due to Covid 19 pandemic, there is an emerging trend that most consumers moving towards online platforms in order to avoid physical contact. Hence, there is an opportunity for companies to use 
Omnichannel approaches. The findings of the study enhance the understanding of Omnichannel approach and provide insights on how companies can adapt Omnichannel approach and whether the consumers accept Omnichannel approach and what factors will affect their preferences in a pandemic situation like Covid 19.

One of the more significant findings to emerge from this study is that consumer behavior towards Omnichannel approach. Companies can use this study as a tool to predict consumer behavior when introducing Omnichannel approach. The evidence from the study suggests that consumers do not consider cost and risk as significant factors when adapting to Omnichannel approach. This will be a major insight for companies since they give their keen attention to consumer perceived costs and risks when introducing new channel approaches. Also, the study indicates channel preferences of consumers and in general, most of the consumers prefer a blend of online and physical channels rather than using online or physical channels alone which will be favorable insights for potential investors on Omnichannel approach.

The present study makes several noteworthy contributions from different perspectives. When considering consumers' point of view, by referring to this study consumers can get a thorough understanding of Omnichannel approach and take their channel selection decisions as knowledgeable consumers. This study has been focused on providing information about applying Omnichannel approach in supermarket sector. Since supermarket sector in Sri Lanka is rapidly developing with technological advancements this will provide valuable insights for supermarket companies, FMCG companies, small and medium entrepreneurs in supermarket sector.

\subsection{Limitations and Future Research}

Present study consists of several limitations that should be addressed in future researches. The study used judgmental sampling technique which is a nonprobabilistic method which cannot generalized research finding to the population of Sri Lanka. Sample is limited to Colombo district and suggested to get the 
sample covering other districts representing all the population with more sample size. Rather than considering only employed individuals, it is suggested to consider unemployed individuals also. Suggested to use both online and physical method for data collection and get the sample covering different age generations. Recommended to extend the study using more variables using updated models and to use qualitative or mix methods. To get better responses, recommended using different data collection methods rather than using online questionnaires using all main languages. Also suggested to extend the study for other industries as well. 


\section{References :}

Aubrey, C., \& Judge, D. (2012). Re-imagine retail: Why store innovation is key to a brand's growth in the 'new normal', digitally connected and transparent world. Journal of Brand Strategy, 1(1), 31-39.

Bodhani, A. (2012). Shops offer the e-tail experience. Engineering and Technology, 7(5), 46-49. https://doi.org/10.1049/et.2012.0512

Berman, B., \& Thelen, S. (2018). Planning and implementing an effective omnichannel marketing program. International Journal of Retail and Distribution Management, 46(7), 598-614. https://doi.org/10.1108/ IJRDM-08-2016-0131

Carvalho, J. L. G. de. (2014). Multichannel at Retail and Omni-Channel: Challenges for Marketing and Logistics. University of São Paulo - USP (Brazil) Business School (43), 159-168.

Davis, F. D., Bagozzi, R. P., \& Warshaw, P. R. (1989). User Acceptance of Computer Technology: A Comparison of Two Theoretical Models. Management Science, 35(8), 982-1003. https://doi.org/10.1287/ mnsc.35.8.982

Delft, V. (2013). Omni Channel Shopping Behaviour During the Customer Journey.

Dissanayake, M. (2020, July 8). 2020 And Beyond: Trends Shaping Supermarkets for The Future from A. Daily News. https://www.dailynewslk/2020/07/08/ finance/222626/2020-and-beyond-trends-shaping-supermakets-futureretrospective-view-past

Emily A. Vogels. (2019). Millennials stand out for their technology use. Pew Research Center. http://www.pewresearch.org/fact-tank/2018/10/19/ 5-charts-on-global-views-of-china/ 
Fornell, C., \& Larcker, D. F. (1981). Evaluating structural equation models with unobservable variables and measurement error. Journal of Marketing Research, 18(1), 39-50. https://doi.org/10.1177/002224378101800104

Hair et al., R. E. A. (2014). Multivariate Data Analysis. In Neuromarketing in India: Understanding the Indian Consumer (Seventh Ed). Pearson Education Limited. https://doi.org/10.4324/9781351269360

Hair, J. F., Sarsted, M., Ringle, C. M., \& Gudergan, S. P. (2017). Advanced issues in partial least squares structural equation modeling. Sage.

Hair, J. F., Risher, J. J., Sarstedt, M., \& Ringle, C. M. (2019). When to use and how to report the results of PLS-SEM. European Business Review, 31(1), 2-24. https://doi.org/10.1108/EBR-11-2018-0203

Kaczorowska-Spychalska, D. (2017). Consumer perspective of omnichannel commerce. Management, 21(2), 95-108. https://doi.org/10.1515/manment-2017-0007

Kazancoglu, I., \& Aydin, H. (2018). An investigation of consumers' purchase intentions towards omni-channel shopping: A qualitative exploratory study. International Journal of Retail and Distribution Management, 46(10), 959-976. https://doi.org/10.1108/IJRDM-04-2018-0074

Kim, C., Mirusmonov, M., \& Lee, I. (2010). An empirical examination of factors influencing the intention to use mobile payment. Computers in Human Behavior, 26(3), 310-322. https://doi.org/10.1016/j.chb.2009.10.013

Konrad Chan. (2020). Asian retailers should consider investing in omnichannel experiences to stay relevant. Singapore Business Review. https://sbr. com.sg/financial-services/commentary/asian-retailers-should-considerinvesting-in-omnichannel-experiences-s

Koufaris, M. (2002). Applying the Technology Acceptance Model and Flow Theory to Online Consumer Behavior. Information Systems Research, 13(2), 205-223. https://doi.org/10.1287/isre.13.2.205.83 
Krejcie, R. v, \& Morgan, D. (1970). Determining Sample Size for Research Activities. The NEA Research Bulletin, 30, 607-610.

Lazaris, C., Vrechopoulos, A., Fraidaki, K., \& Doukidis, G. (2014). Exploring the "Omnichannel" Shopper Behaviour. AMA SERVSIG, International Service Research Conference, 13-15 June, October. https://doi.org/ 10.13140/2.1.1278.2089

Malhotra, N. K., Nunan, D., \& Birks, D. F. (2017). Marketing Research an Applied Approach.

Muhamed, M. (2019). Multichannel Retailing: How Omni-channel Retail Helps Build Loyalty. LMD. https://lmd.lk/loyalty-doesnt-come-easy/

Piotrowicz, W., \& Cuthbertson, R. (2014). Introduction to the special issue information technology in retail: Toward omnichannel retailing. International Journal of Electronic Commerce, 18(4), 5-16. https://doi. org/10.2753/JEC1086-4415180400

Plouffe, C. R., Hulland, J. S., \& Vandenbosch, M. (2001). Research Report: Richness Versus Parsimony in Modeling Technology Adoption Decisions Understanding Merchant Adoption of a Smart Card-Based Payment System. Information Systems Research, 12(2), 208-222. https://doi. org/10.1287/isre.12.2.208.9697

Podsakoff, P. M., MacKenzie, S. B., Lee, J. Y., \& Podsakoff, N. P. (2003). Common method biases in behavioral research: A critical review of the literature and recommended remedies. Journal of Applied Psychology, 88(5), 879-903. https://doi.org/10.1037/0021-9010.88.5.879

Rigby, D. K. (2011). The Future of Shopping. In Harvard Business Review (Vol. 84, Issue 9). https://doi.org/10.1007/978-1-349-14797-7

Samarasinghe, R. (2017). The influence of cultural values on green purchase behaviour. Marketing Intelligence and Planning, 35(3), 377-396. https:// doi.org/10.1108/MIP-08-2016-0131 
Saunders, M., Lewis, P., \& Thornhill, A. (2019). Understanding research philosophy and approaches to theory development. In Research Methods for Business Students (Issue March).

Sekaran. (2016). Research Methods for Business: A Skill Building Approach (Seventh Ed).

Šerić, M., Gil-Saura, I., \& Ruiz-Molina, M. E. (2014). How can integrated marketing communications and advanced technology influence the creation of customer-based brand equity? Evidence from the hospitality industry. International Journal of Hospitality Management, 39, 144-156. https://doi.org/10.1016/j.ijhm.2014.02.008

Silva, S. C. e, Martins, C. C., \& Sousa, J. M. de. (2018). Omnichannel approach: Factors affecting consumer acceptance. Journal of Marketing Channels, 25(1-2), 73-84. https://doi.org/10.1080/1046669x.2019.1647910

Sopadjieva, E., Dholakia, U. M., \& Benjamin, B. (2017). A Study of 46,000 Shoppers Shows That Omnichannel Retailing Works. Harvard Business Review, August 2016, 7-10.

Tambo, T. (2015). Omni-channel retail information systems. Encyclopedia of Information Science and Technology, Third Edition (Pp. 874-882). IGI Global.

The Retail Feedback Group. (2020). US Online \& In-Store Grocery Shopping Study 2020. Supermarket Perimeter. https://www.supermarketperimeter. com/articles/5325-omnichannel-shoppers-increasing-amid-pandemic

Venkatesh et al. (2012). Consumer Acceptance and Use of Information Technology: Extending the Unified Theory of Acceptance and Use of Technology. MIS Quarter, 34(3), 157-178.

Verhoef, P. C., Neslin, S. A., \& Vroomen, B. (2007). Multichannel customer management: Understanding the research-shopper phenomenon. International Journal of Research in Marketing, 24(2), 129-148. https://doi.org/10.1016/j.ijresmar.2006.11.00 
Verhoef, P. C., Neslin, S. A., \& Vroomen, B. (2007). Multichannel customer management: Understanding the research-shopper phenomenon. International Journal of Research in Marketing, 24(2), 129-148. https://doi.org/10.1016/j.ijresmar.2006.11.00

Verhoef, P. C., Neslin, S. A., \& Vroomen, B. (2007). Multichannel customer management: Understanding the research-shopper phenomenon. International Journal of Research in Marketing, 24(2), 129-148. https://doi.org/10.1016/j.ijresmar.2006.11.002

Verhoef, P. C., Neslin, S. A., \& Vroomen, B. (2007). Multichannel customer management: Understanding the research-shopper phenomenon. International Journal of Research in Marketing, 24(2), 129-148. https://doi.org/10.1016/j.ijresmar.2006.11.002

Verhoef, P. C., Kannan, P. K., \& Inman, J. J. (2015). From Multi-Channel Retailing to Omni-Channel Retailing. Introduction to the Special Issue on Multi-Channel Retailing. Journal of Retailing, 91(2), 174-181. https://doi.org/10.1016/j.jretai.2015.02.005

Wu, J. H., \& Wang, S. C. (2005). What drives mobile commerce? An empirical e valuation of the revised technology acceptance model. Information and Management, 42(5), 719-729. https://doi.org/10.1016/j.im.2004.07.001 